\title{
Substrate specificity and regioselectivity of fungal AA9 lytic polysaccharide monooxygenases secreted by Podospora anserina
}

\author{
Chloé Bennati-Granier ${ }^{1,2+}$, Sona Garajova ${ }^{1,2,3 \dagger}$, Charlotte Champion ${ }^{1,2}$, Sacha Grisel ${ }^{1,2}$, Mireille Haon 1,2, \\ Simeng Zhou ${ }^{1,2}$, Mathieu Fanuel ${ }^{4}$, David Ropartz ${ }^{4}$, Hélène Rogniaux ${ }^{4}$, Isabelle Gimbert ${ }^{1,2}$, Eric Record ${ }^{1,2}$ \\ and Jean-Guy Berrin ${ }^{1,2^{*}}$
}

\begin{abstract}
Background: The understanding of enzymatic polysaccharide degradation has progressed intensely in the past few years with the identification of a new class of fungal-secreted enzymes, the lytic polysaccharide monooxygenases (LPMOs) that enhance cellulose conversion. In the fungal kingdom, saprotrophic fungi display a high number of genes encoding LPMOs from family AA9 but the functional relevance of this redundancy is not fully understood.

Results: In this study, we investigated a set of AA9 LPMOs identified in the secretomes of the coprophilous ascomycete Podospora anserina, a biomass degrader of recalcitrant substrates. Their activity was assayed on cellulose in synergy with the cellobiose dehydrogenase from the same organism. We showed that the total release of oxidized oligosaccharides from cellulose was higher for PaLPMO9A, PaLPMO9E, and PaLPMO9H that harbored a carbohydrate-binding module from the family CBM1. Investigation of their regioselective mode of action revealed that PaLPMO9A and PaLPMO9H oxidatively cleaved at both C1 and C4 positions while PaLPMO9E released only C1-oxidized products. Rapid cleavage of cellulose was observed using PaLPMO9H that was the most versatile in terms of substrate specificity as it also displayed activity on cello-oligosaccharides and $\beta$-(1,4)-linked hemicellulose polysaccharides (e.g., xyloglucan, glucomannan).
\end{abstract}

Conclusions: This study provides insights into the mode of cleavage and substrate specificities of fungal AA9 LPMOs that will facilitate their application for the development of future biorefineries.

Keywords: AA9, LPMO, Cellobiose dehydrogenase, Oxidized cello-oligosaccharides, Cellulose, Hemicellulose, Oxidative cleavage, Lignocellulose, Biomass, Biorefinery

\section{Background}

Lignocellulosic biomass is a high-potential renewable resource for the production of 2nd-generation biofuels and platform molecules for the chemical industry. The natural resistance of plant cell wall to microbial and enzymatic deconstruction, collectively known as "biomass recalcitrance", is largely responsible for the high cost of industrial processes [1]. Although plant biomass degradation by fungi has been studied extensively, our knowledge

\footnotetext{
* Correspondence: jean-guy.berrin@univ-amu.fr

${ }^{\dagger}$ Equal contributors

'INRA, UMR1163 Biodiversité et Biotechnologie Fongiques, Faculté des Sciences de Luminy, ESIL Polytech, F-13288 Marseille, France

${ }^{2}$ Polytech Marseille, Aix Marseille Université, F-13288 Marseille, France

Full list of author information is available at the end of the article
}

of the enzyme systems used to degrade cellulose has changed dramatically in the last 5 years. Indeed, a new class of secreted enzymes known as lytic polysaccharide monooxygenases (LPMOs) was identified due to its "boosting effect" on enzymatic polysaccharide conversion [2, 3]. Intensive efforts have started to unveil their function in the oxidative degradation of cellulose [4-8] and other plant polysaccharides, i.e., hemicellulose [9] and starch $[10,11]$.

All LPMOs share a common structural fold with a flat surface where binding with the substrate occurs mostly via stacking interactions with planar aromatic residues. A type II copper ion exposed at the surface is coordinated by the nitrogen atoms of two highly conserved histidine 
residues, one of which corresponds to the $\mathrm{N}$-terminal histidine. Analysis of LPMOs' reaction products showed that they produced C1- and/or C4-oxidized oligomers. According to the preferred site of oxidation, three classes of AA9 LPMOs were described, type 1 and type 2 oxidizing at the $\mathrm{C} 1$ and the $\mathrm{C} 4$, respectively, and type 3 oxidizing at both the $\mathrm{C} 1$ and $\mathrm{C} 4$ carbon atoms of glucose $[8,12,13]$. C6 oxidation has been suggested for Thermoascus aurantiacus TaGH61A [7] and Podospora anserina PaGH61B [14] although it is a matter of debate since the 6hexodialdoses have the same molecular weight as that of the corresponding 4-ketoaldioses.

LPMOs are classified into four auxiliary activity (AA) families, AA9 (formerly GH61), AA10 (formerly CBM33), AA11, and AA13 of the Carbohydrate-Active enZyme database $[15,16]$ (CAZy; http://www.cazy.org). The AA10 family contains mainly enzymes of bacterial and viral origin that cleave cellulose and chitin mostly at the $\mathrm{C} 1$ position $[17,18]$. The LPMOs classified in the AA11 and AA13 families, respectively, cleave chitin and starch and share important structural features with the two previously characterized families $[10,11,18]$.

The oxidative cleavage performed by LPMOs is occurring in the presence of small redox-active molecules such as ascorbic acid, reduced glutathione, or gallate $[2,4,7,17]$. The peculiarity of fungal AA9 LPMOs is their action in concert with cellobiose dehydrogenases $(\mathrm{CDHs})$ since their association resulted in redoxmediated glycosidic bond cleavage in cellulose, assuming a key role of this oxidative system in fungi $[5,6,8$, 14, 19]. All known CDHs fall into two related subgroups. Class I members are represented by sequences from basidiomycetes whereas class II comprises longer, more complex sequences from ascomycete fungi [20]. The effectiveness of LPMO/CDH synergy depends on enzyme concentrations and the type of substrate used [14].

The family AA9 comprises about 300 fungal members widely distributed in the genomes of most ascomycetes and basidiomycetes. A striking feature is the extreme expansion in genes encoding AA9s observed in some genomes, which can reach more than 30 homologous gene models per species. A total of 33 candidate AA9s were assigned in $P$. anserina $[16,21]$. Only two $(P a G H 61 \mathrm{~A}$ and $P a G H 61 B$ ) were functionally characterized for their potential to degrade cellulose oxidatively [14]. Therefore, this redundancy raises the question of the functional relevance at the organism level, i.e., functional redundancy or functional diversification or fine-tuned regulation of alternative genes and/or adaptations to the degradation of the substrates. AA9 LPMOs are frequently multimodular bearing a CBM1 at their $\mathrm{C}$ terminus. Post-genomic analyses of saprophytic fungi have shown that AA9 LPMOs' isoforms are specifically secreted during degradation of lignocellulosic substrates [22-27]. In this study, we focused on AA9 LPMOs identified in the secretome of $P$. anserina that was shown to significantly improve the saccharification yield of steam-exploded wheat straw [26]. The specificity and regioselectivity of these fungal AA9 LPMOs for the degradation of plant cell wall carbohydrates were investigated using complementary approaches.

\section{Results}

Heterologous expression of five AA9 LPMOs and one CDH from $P$. anserina

In order to give insights into the functional relevance of $P$. anserina LPMOs, we selected seven AA9 LPMOs and one CDH, i.e., PaLPMO9A [14], PaLPMOC (protein ID CAP68173), PaLPMO9D (protein ID CAP66744), PaLPMO9E (protein ID CAP67740), PaLPMO9F (protein ID CAP71839), PaLPMO9G (protein ID CAP73072), PaLP$\mathrm{MO} 9 \mathrm{H}$ (protein ID CAP61476), and $\mathrm{PaCDHB}$ (protein ID CAP61651) based on our previous analysis of $P$. anserina secretomes [26]. The $\mathrm{PaCDHB}$ was selected because it was more abundant in the secretomes compared to $\mathrm{PaCDHA}$, which was previously characterized [28]. In all $P$. anserina LPMOs selected, the three amino acids (two histidines with one at the first position and one tyrosine) involved in copper coordination were strictly conserved (Additional file 1: Figure S1). However, the $P$. anserina LPMOs selected are quite diverse in sequence with identities ranging from 23 to $53 \%$ within the main catalytic domain (Additional file 1: Table S1). PaLPMO9A, PaLPMO9E, and PaLPMO9H are multimodular enzymes with a carbohydrate-binding module from the family CBM1 at their C terminus (Fig. 1a).

Because the strictly conserved $\mathrm{N}$-terminal histidine residue is essential for their function, the $P$. anserina lpmo genes, codon optimized for expression in Pichia pastoris, were inserted into the pPICZ $\alpha \mathrm{A}$ expression plasmid immediately after the sequence encoding the signal peptide. Following induction of selected $P$. pastoris transformants, all the $P$. anserina AA9s (except PaLPMO9C) were successfully produced and purified to homogeneity. Electrophoretic analysis revealed that purified PaLPMO9s displayed apparent molecular masses that were higher than the theoretical ones (Additional file 1: Figure S2). This might be partly due to $\mathrm{O}$ - and $\mathrm{N}$-glycosylation that are predicted to be abundant in all of the PaLPMO9s, especially the ones bearing serine/threonine-rich linker regions between the catalytic and the CBM1 modules that contain multiple glycosylation sites as already observed in other modular fungal CAZymes [29].

A peculiarity of fungal AA9 LPMOs is the methylation of their N-terminal histidine at the imidazole Ne2 [18, 27]. To investigate whether PaLPMO9s harbored this unusual 


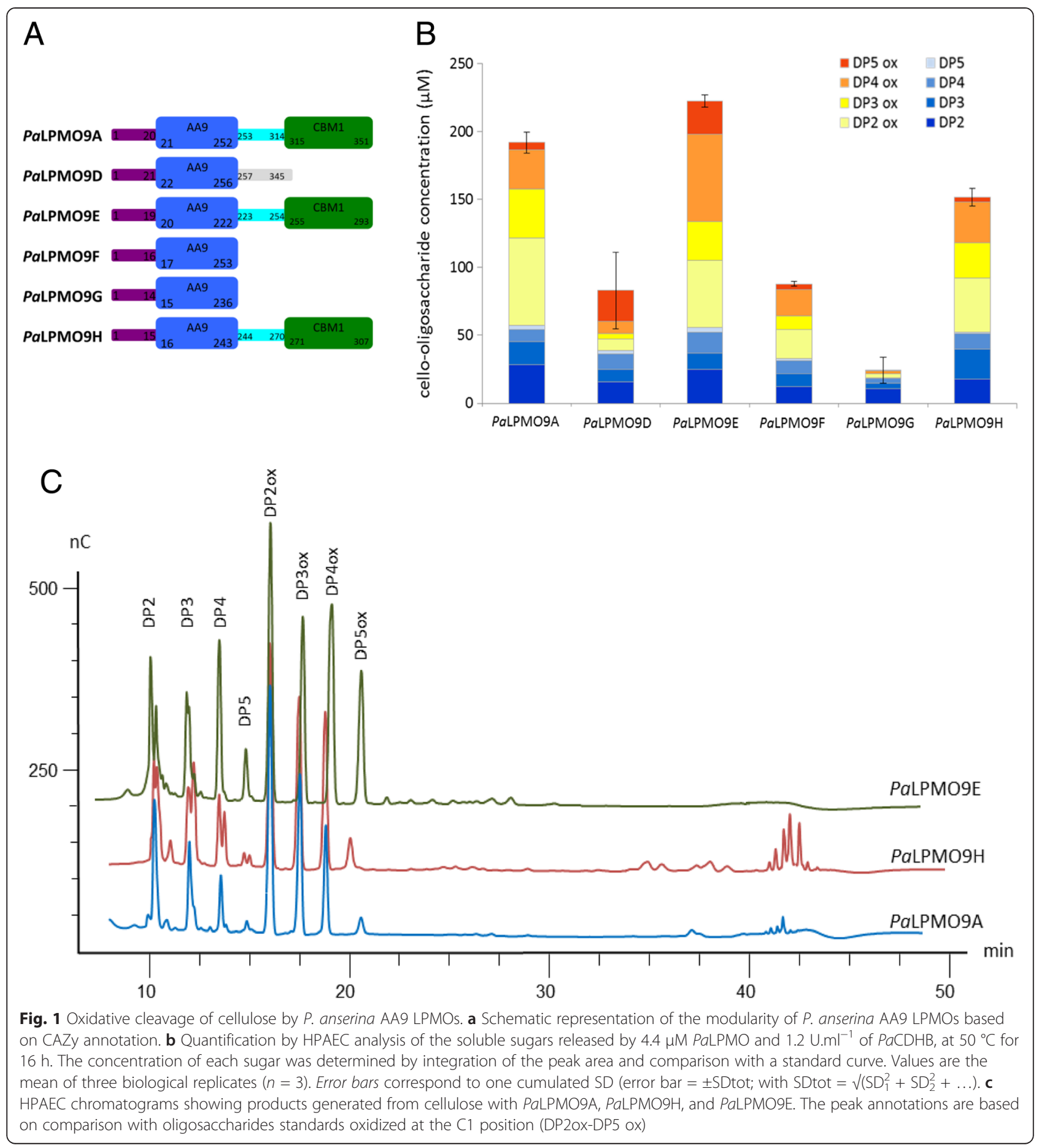

post-translational modification, mass spectrometry (MS) analyses on tryptic digests of PaLPMO9E and PaLP$\mathrm{MO} 9 \mathrm{H}$ were performed. MS spectra supported that the strictly conserved N-terminal histidine residue was not methylated (Additional file 1: Table S2).

To assess the functionality of these copper monooxygenases, we evaluated their capacity to produce $\mathrm{H}_{2} \mathrm{O}_{2}$ when activated by ascorbate in the absence of a carbohydrate substrate. Although $\mathrm{H}_{2} \mathrm{O}_{2}$ production is not the intended natural enzyme reaction, it can be used to calculate specific activities. Specific activities measured with enzymes purified to homogeneity were ranging from $0.01{\mathrm{U} . g^{-1}}^{\text {(PaLP- }}$ MO9A) to $1.95{\mathrm{U} . g^{-1}}^{-P a L P M O 9 E}$ ) (Table 1). No significant $\mathrm{H}_{2} \mathrm{O}_{2}$ production was detected for PaLPMO9G.

In parallel, $\mathrm{PaCDHB}$ was also heterologously expressed in $P$. pastoris. It exhibited a specific activity of $8.6 \mathrm{U} \cdot \mathrm{mg}^{-1}$ 
Table 1 Biochemical and enzymatic characteristics of the enzymes used in this study

\begin{tabular}{|c|c|c|c|c|c|c|}
\hline \multirow[t]{2}{*}{ Enzymes } & \multirow{2}{*}{$\begin{array}{l}\text { GenBank } \\
\text { ID }\end{array}$} & \multirow[t]{2}{*}{ Modularity } & \multirow{2}{*}{$\begin{array}{l}\text { Predicted } \\
\text { function }\end{array}$} & \multirow[t]{2}{*}{$S A^{a}\left(U \cdot g^{-1}\right)$} & \multicolumn{2}{|c|}{ Competitive inhibition assay ( $\%$ of residual activity) } \\
\hline & & & & & PASC & CMC \\
\hline $\mathrm{PaCDHB}$ & CAP61651 & AA3_1-AA8 & $\mathrm{CDH}$ & 8.6 & N.D. & N.D. \\
\hline PaLPMO9A & CAP73254 & AA9-CBM1 & LPMO & $0.010 \pm 0.001$ & $7.6 \pm 1.1$ & $97.9 \pm 2.1$ \\
\hline PaLPMO9D & CAP66744 & AA9 & LPMO & $0.083 \pm 0.005$ & $75.1 \pm 7.5$ & $73.2 \pm 8.5$ \\
\hline PaLPMO9E & CAP67740 & AA9-CBM1 & LPMO & $1.95 \pm 0.04$ & $18.4 \pm 4.2$ & $47.0 \pm 1.3$ \\
\hline PaLPMO9F & CAP71839 & AA9 & LPMO & $0.028 \pm 0.003$ & $16.9 \pm 1.9$ & $100.0 \pm 4.8$ \\
\hline PaLPMO9G & CAP73072 & AA9 & LPMO & n.d. & N.D. & N.D. \\
\hline PaLPMO9H & CAP61476 & AA9-CBM1 & LPMO & $0.42 \pm 0.03$ & $7.2 \pm 1.4$ & $6.1 \pm 0.8$ \\
\hline
\end{tabular}

n.d. no production of $\mathrm{H}_{2} \mathrm{O}_{2}$ detected using the Amplex Red assay, N.D. not determined

${ }^{\text {a S}}$ Specific activity was measured using DCPIP $\left(\mathrm{pH} 5,30^{\circ} \mathrm{C}\right)$ for $\mathrm{PaCDHB}$ and the Amplex Red assay for PaLPMOs $\left(\mathrm{pH} 6,30^{\circ} \mathrm{C}\right)$

on cellobiose when dichlorophenol indophenol (DCPIP) was used as electron acceptor and was able to successfully oxidize cello-oligosaccharides from DP2 to DP6 yielding the corresponding aldonic acid oligosaccharides (oxidized at $\mathrm{C} 1$ ) that were used as standards for the present study.

\section{LPMOs bearing a CBM1 module display higher cellulose degradation capabilities}

To check their functionality, PaLPMO9s were tested for their ability to produce $\mathrm{H}_{2} \mathrm{O}_{2}$ in the presence of a range of cellulosic derivatives using the Amplex Red assay (see Material and Methods) described by Isaksen et al. [30] and Kittl et al. [31]. Indeed, the $\mathrm{H}_{2} \mathrm{O}_{2}$ production of LPMOs in the absence of carbohydrate substrate is a futile reaction that is less likely to happen when the substrate is available. For all PaLPMO9s tested, the production of $\mathrm{H}_{2} \mathrm{O}_{2}$ decreased in the presence of phosphoric acid swollen cellulose (PASC) and carboxymethyl cellulose (CMC). Except PaLPMO9D, the presence of PASC almost completely reduced the $\mathrm{H}_{2} \mathrm{O}_{2}$ production while CMC significantly reduced $\mathrm{H}_{2} \mathrm{O}_{2}$ production for PaLPMO9E and PaLPMO9H (Table 1).

PaLPMOs were further assayed for their ability to cleave cellulose in the presence of $\mathrm{PaCDHB}$. High performance anion exchange chromatography (HPAEC) analysis, following the method developed for the detection of both non-oxidized and oxidized species [32], indicated that the combination of PaLPMO9s with $\mathrm{PaCDHB}$ released a mixture of non-oxidized and oxidized soluble cello-oligosaccharides that were quantified based on standards. The degree of polymerization (DP) ranged from DP2 to DP5 for non-oxidized oligosaccharides and from DP2ox to DP5ox for the oxidized products (Fig. 1b, c). The total release of non-oxidized and oxidized oligosaccharides was more efficient for PaLPMO9A, PaLPMO9E, and PaLPMO9H that possess a CBM1 module. Analyses of chromatograms indicated differences in terms of oxidized products (Fig. 1c). For instance, $\mathrm{PaLPMO9E}$ released oligosaccharides corresponding to aldonic acid oligosaccharides (C1-oxidized) while for PaLPMO9A and PaLPMO9H, peaks eluting later were also observed (Fig. 1c).

\section{Oxidative regioselectivity of PaLPMO9A, PaLPMO9E, and PaLPMO9H}

To determine the nature of oxidation of PaLPMO9A, PaLPMO9E, and PaLPMO9H, we performed sequential treatments of cellulose by LPMOs in the presence of ascorbate followed by addition of $\mathrm{PaCDHB}$, which oxidizes only at the reducing end ( $\mathrm{C} 1$ carbon of the glucose unit) of cellobiose and longer cello-oligosaccharides. In the case of PaLPMO9E, only C1-oxidized oligosaccharides were detected in both the ascorbate and $\mathrm{PaCDHB}$ conditions (not shown). In the case of PaLPMO9A and $\mathrm{PaLPMO}$ \% , the ascorbate condition yielded production of C1-oxidized oligosaccharides (DP2-DP4) as well as other oxidized species observed at 27, 38, and $41 \mathrm{~min}$ (Fig. 2). For both PaLPMO9A and PaLPMO9H, addition of $\mathrm{PaCDHB}$ led to an increase of $\mathrm{C} 1$-oxidized oligosaccharides and to a clear shift of products eluting after 25 min. Indeed, oxidized species at 27, 38, and $41 \mathrm{~min}$ disappeared with the concomitant apparition of new peaks at $39 \mathrm{~min}$ and around 42-44 min, which may correspond to a $\mathrm{C} 1-\mathrm{C} 4$-double-oxidized DP2 and longer double-oxidized products, respectively, based on the analysis of Isaksen et al. [30]

As no C4-oxidized standards are available, mass spectrometry was used to confirm the position of oxidation. Analysis of the product mixture generated from PASC with PaLPMO9H confirmed the presence of DP2- to DP5-oxidized and non-oxidized cello-oligosaccharides with products potentially corresponding to a ketone or gem-diol at the non-reducing end $(m / z-2$ or $m / z+16$, respectively) and to a lesser extent double-oxidized products $(m / z+32)$ (Fig. 3a). To confirm the position of oxidation generated by $\mathrm{PaLPMO} 9 \mathrm{H}$, electrospray ionisation (ESI) MS/MS was performed on DP4 monooxidized product species (ions at $m / z+687$ and $m / z+705$, Fig. 3b, c). Interpretation of the fragmentation spectra was based on the previous observation by Isaksen et al. [30] 


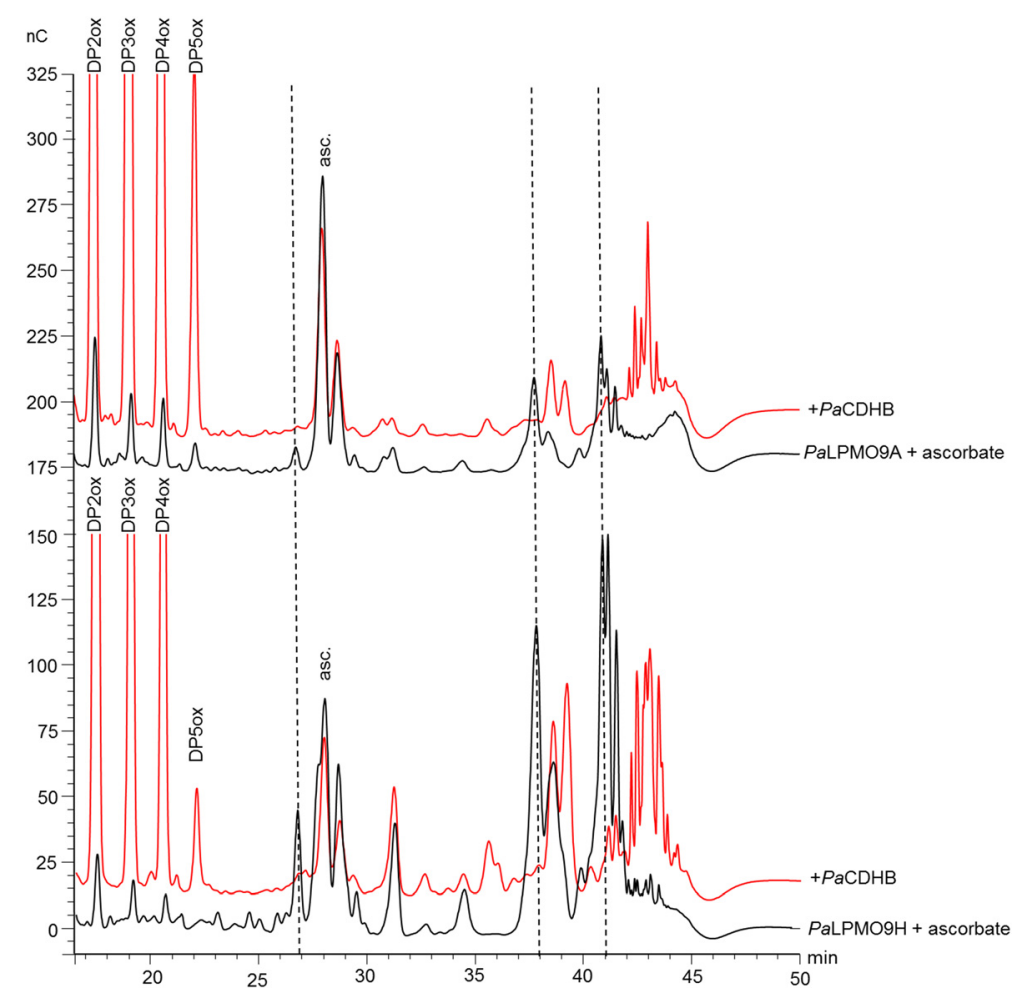

Fig. 2 Analysis of degradation products generated by PaLPMO9A and PaLPMO9H. The HPAEC chromatograms of the oligosaccharides released upon degradation of $0.1 \%$ PASC with $4.4 \mu \mathrm{M}$ PaLPMO in the presence of $1 \mathrm{mM}$ ascorbate, at $50{ }^{\circ} \mathrm{C}$ for $16 \mathrm{~h}$ (in black) followed by the incubation with $1.2 \mathrm{U} \cdot \mathrm{ml}^{-1}$ of $\mathrm{PaCDHB}$ at $50{ }^{\circ} \mathrm{C}$ for $8 \mathrm{~h}$ (in red). The peak annotations are based on comparison with oligosaccharides standards oxidized at the C1 position (DP20x-DP50x). Coelution of DP10x with DP3 and DP20x with DP6 was observed. Peaks eluting at 27, 38, and 41 min are annotated with dotted lines

that a gem-diol form at the non-reducing end (C4 position) leads to a double loss of water. This double loss is very clearly observed on the MS2 spectrum of the species at $m / z 705.22$ (Fig. 3c), suggesting that this species corresponds to a gem-diol form at the non-reducing end. In contrast, a single water loss is observed on Fig. $3 \mathrm{~b}$ $(m / z+687)$, consistent with a ketone form at the $\mathrm{C} 4$ position of the non-reducing end, in addition to several characteristic fragment ions supporting this ketone structure $\left({ }^{2,5} \mathrm{X}_{3},{ }^{1,5} \mathrm{X}_{3},{ }^{1,5} \mathrm{X}_{2}\right)$. Figure $3 \mathrm{~d}$ displays the MS2 spectrum recorded for the species at $m / z+721$.21. Based on the mass accuracy of the instrument, this mass was unequivocally attributed to the sodiated ion of the doubly oxidized DP4. Again, the fragmentation pattern was interpreted following the statements of Isaksen et al. [30], as well as by the observation of some specific fragments. This has led us to propose two structures presumably present as a mixture: in the first one, the two oxidations are brought by the non-reducing end. This is evidenced by the two ions at $m / z+527.17\left(\mathrm{Y}_{3}\right)$ and $m / z+555.16\left({ }^{1,5} \mathrm{X}_{3}\right)$, indicating three consecutive non-oxidized glucose units in this structure, thereby suggesting that the fourth one is doubly oxidized. The specific fragment at $m / z+555.16\left({ }^{1,5} \mathrm{X}_{3}\right)$ further indicates that the doubly oxidized unit is the glucose at the nonreducing end. Some fragment ions of the spectrum cannot arise from the previous form and indicate the presence of a second structure. We propose that this structure corresponds to the DP4 in which one oxidation is brought by the non-reducing end while the second one is located at the reducing end. This is supported for example by the ions at $m / z+525.15\left(\mathrm{~B}_{3}\right)$ and $m / z+543.17\left(\mathrm{C}_{3}\right)$, which masses correspond to two consecutive non-modified glucose units and one oxidized glucose unit. Note, however, that the exact positioning of the oxidation at the reducing end could not be ascertained between the $\mathrm{C} 1, \mathrm{C} 2, \mathrm{C} 3$, or C6 positions. A similar mass spectrometry analysis of the products released from PASC using the PaLPMO9E was performed. It revealed only the presence of $\mathrm{C} 1$-oxidized species (Additional file 1: Figure S3).

In conclusion, product analyses indicate that PaLPMO9A and PaLPMO9H cleaved cellulose at both the C1 and $\mathrm{C} 4$ glycosidic positions while $\mathrm{PaLPMO}$ E was specific for the $\mathrm{C} 1$ position only.

\section{Time-course monitoring of cellulose cleavage}

Fungal members of the GH61 family have been described for many years as "weak endoglucanases" [33, 34] as the 


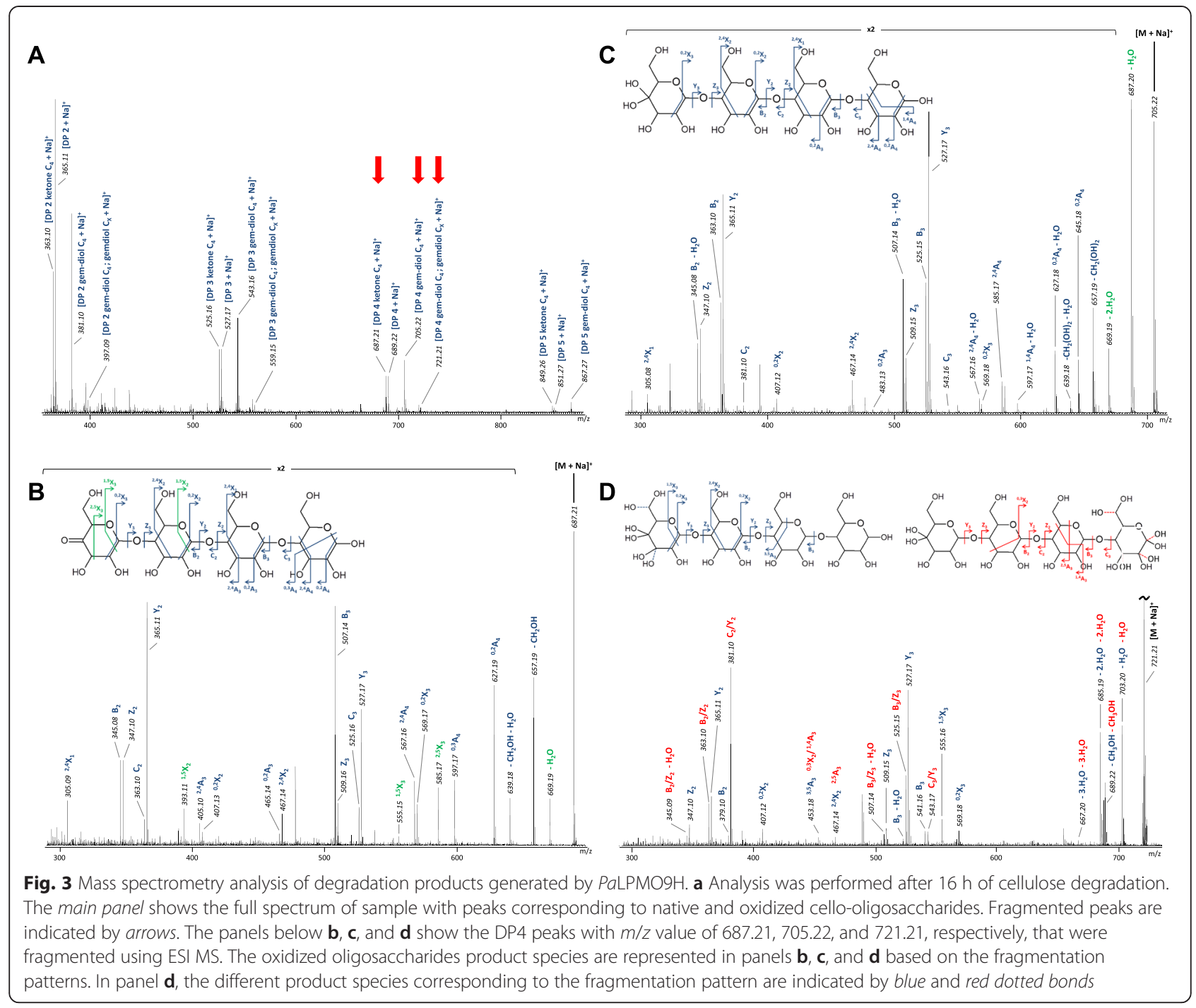

activity was several orders of magnitude lower than what had been observed in other endoglucanases. Since the discovery of the functional nature of AA9 LPMOs, their enzymatic activity is still described as slow for the release of soluble products $[4,12,35]$ and therefore, their activity is usually measured using long-lasting incubations (overnight incubations). Using PaLPMO9H, we followed over time the release of soluble oligosaccharides (oxidized and non-oxidized) from cellulose using HPAEC-PAD. Significant amounts of $\mathrm{C} 1$ - and C4-oxidized oligosaccharides were detected in the early stages of incubation $(1,2$, and $3 \mathrm{~h}$ ), which indicate that several cleavages had already occurred. The concentration of oxidized and non-oxidized oligosaccharides increased gradually up to $48 \mathrm{~h}$ with cellobionic acid as the main end product (Fig. 4). At the end of the reaction, around $10 \%$ of cellulose was converted into soluble products (although it was not possible to quantify the concentration of C4-oxidized oligosaccharides). Noteworthy, the concentration of C1- oxidized cellopentaose (DP5ox) declined after $9 \mathrm{~h}$ of incubation (Fig. 4), which could indicate a potential action of $\mathrm{PaLPMO9H}$ on soluble oligosaccharides in a similar way as was observed for NcLPMO9C [30].

\section{PaLPMO9H displays broad specificity against cello- oligosaccharides and $\beta$ - $(1,4)$-linked polysaccharides}

Among the set of $\mathrm{PaLPMO} 9 \mathrm{~s}$ studied, $\mathrm{PaLPMO} 9 \mathrm{H}$ was the only one displaying inhibition of $\mathrm{H}_{2} \mathrm{O}_{2}$ production in the presence of cellohexaose (DP6), cellopentaose (DP5), and cellotetraose (DP4) with the residual $\mathrm{H}_{2} \mathrm{O}_{2}$ production of 4.8, 6.5, and 19.4\%, respectively (Fig. 5a). However, no decrease in $\mathrm{H}_{2} \mathrm{O}_{2}$ production was observed in the presence of non-cellulosic oligosaccharides [mannohexaose, laminarihexaose, xyloglucan-derived heptasaccharide (XXXG), and mixed linkage $\beta$-(1-3,1-4)-tetraose] (Fig. 5a) suggesting that $\mathrm{PaLPMO} 9 \mathrm{H}$ is not active on these oligosaccharide substrates. To verify these findings, we used the HPAEC method to detect native and 

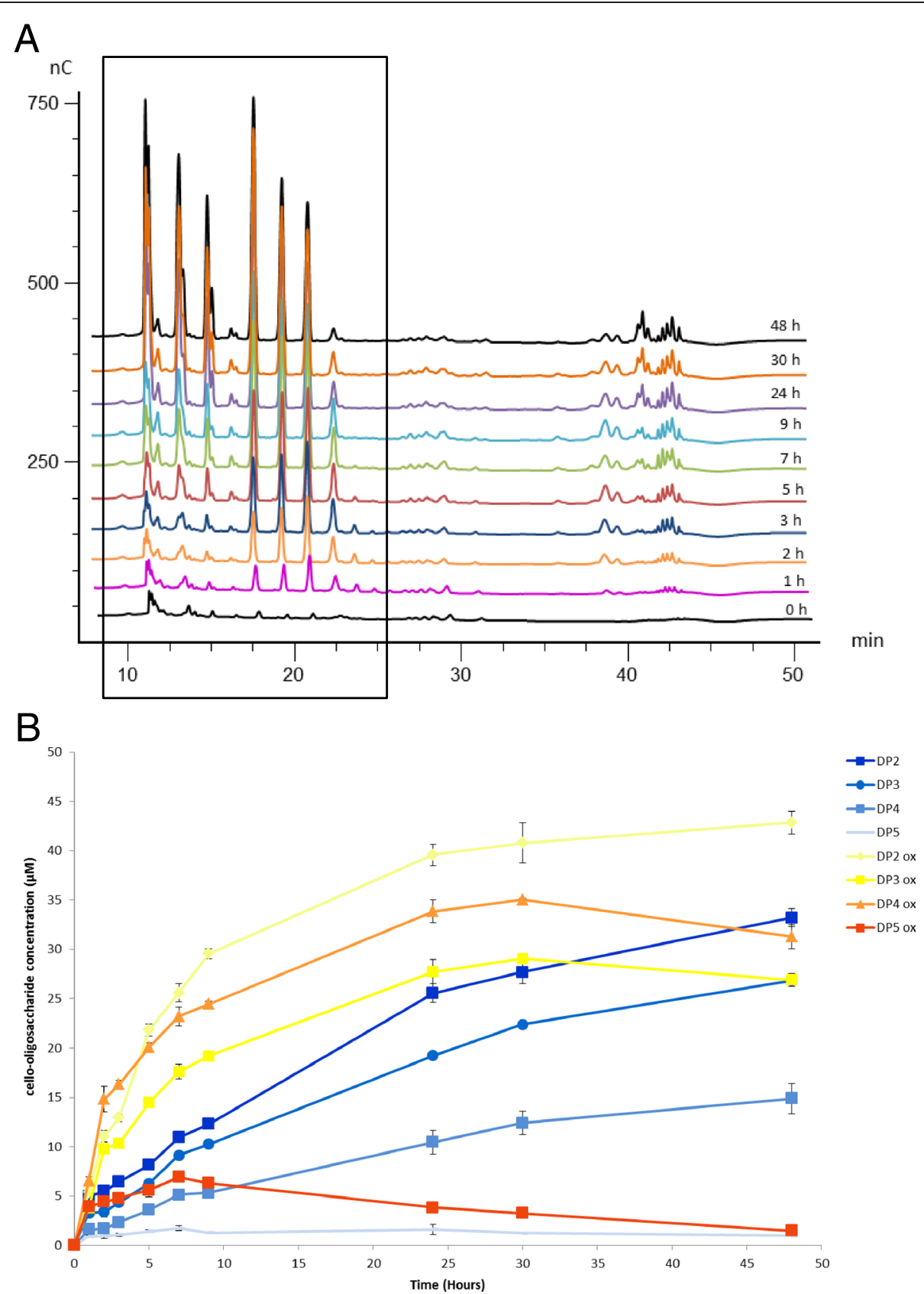

Fig. 4 Time-course analysis of the products released from cellulose by PaLPMO9H. a The HPAEC chromatograms show products generated from cellulose with $4.4 \mu \mathrm{M} \mathrm{PaLPMO} 9 \mathrm{H}$ and $1.2 \mathrm{U} \cdot \mathrm{ml}^{-1}$ of $\mathrm{PaCDHB}$, at $50{ }^{\circ} \mathrm{C}$ for $1,2,3,5,7,9,24,30$, and $48 \mathrm{~h}$ of incubation. b A quantification by HPAEC analysis of the soluble sugars (aldonic acid and non-oxidized oligosaccharides) released by PaLPMO9H over time has been conducted. The concentration of each sugar was determined by integration of the peak area and comparison with a standard curve. Values are the mean of three biological replicates $(n=3)$. Error bars correspond to one cumulated SD (error bar $= \pm$ SDtot; with SDtot $=\sqrt{ }\left(\mathrm{SD}_{1}^{2}+\mathrm{SD}_{2}^{2}+\ldots\right)$

oxidized species using cellopentaose and cellohexaose as substrates. In the presence of $\mathrm{PaCDHB}$ or ascorbic acid, PaLPMO9H was able to oxidatively cleave cellohexaose since the peak decreased significantly with the concomitant apparition of oxidized and non-oxidized species (Fig. 5b). The ascorbate condition yielded the release of C1-oxidized oligosaccharides (DP3ox and DP4ox) as well as presumably C4-oxidized species observed at 27 and $38 \mathrm{~min}$ (Fig. 5b). The use of $\mathrm{PaCDHB}$ as a donor of electron led to an increase of C1-oxidized oligosaccharides and to the apparition of a major peak eluting at $39 \mathrm{~min}$ which may correspond to a double-oxidized DP2 (C1-C4) and to longer double-oxidized products $(\mathrm{C} 1-\mathrm{C} 4)$ eluting around 42-44 min (Fig. 5b) as observed for cellulose 
A
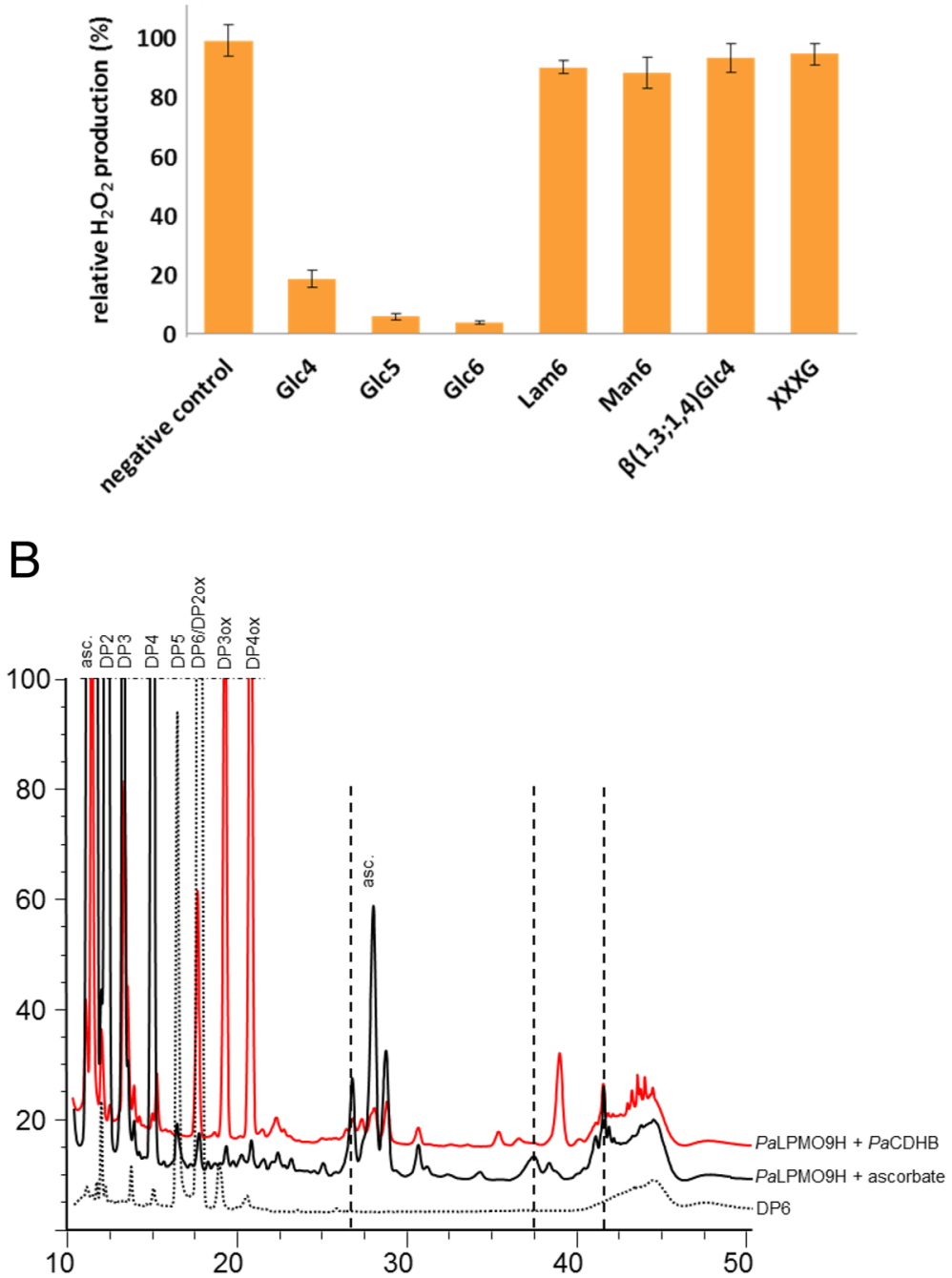

Fig. $5 \mathrm{PaLPMO} 9 \mathrm{H}$ activity on oligosaccharide substrates. a Generation of $\mathrm{H}_{2} \mathrm{O}_{2}$ by $\mathrm{PaLPMO} 9 \mathrm{H}$ in the presence and/or absence of various oligosaccharides substrates. Glc4, cellotetraose; Glc5, cellopentaose; Glc6, cellohexaose; Lam6, laminarinhexaose; Man6, mannohexaose; $\beta(1,3 ; 1,4) G l c 4, \beta(1,3 ; 1,4)$-glucotetraose (G4G3G4G); XXXG, xyloglucan-derived heptasaccharide. b HPAEC chromatogram of products released from cellohexaose by action of PaLPMO9H in the presence of ascorbic acid (in black) or PaCDHB (in red) with the same labeling of peaks as Fig. 2

(Fig. 2). A similar pattern of products was obtained when cellopentaose was used as substrate (Additional file 1: Figure S4).

To further investigate the substrate specificities of PaLPMO9s, we used the method based on $\mathrm{H}_{2} \mathrm{O}_{2}$ detection to rapidly screen the ability of PaLPMO9s to interact with a range of potential hemicellulosic substrates. We investigated the differences in $\mathrm{H}_{2} \mathrm{O}_{2}$ production in the presence of CMC, curdlan, barley $\beta$-glucan, glucomannan, lichenan, pectin, xylan, and xyloglucan (XG) at three different concentrations ranging from 0.01 to $0.1 \%(\mathrm{w} / \mathrm{v})$. The repression in $\mathrm{H}_{2} \mathrm{O}_{2}$ production tested at different substrate concentrations was significant only for $\mathrm{PaLPMO}$ H in the presence of $\mathrm{CMC}$, barley $\beta$-glucan, glucomannan, lichenan, and XG (Fig. 6a) while curdlan, pectin, and xylan had no effect on $\mathrm{H}_{2} \mathrm{O}_{2}$ production for any of the PaLPMO9s tested (not shown). The oxidative cleavage of XG was further investigated using HPAEC. It revealed that a mixture of non-oxidized oligosaccharides, some of which match XXX and XXXG species, eluting at 26 and $31 \mathrm{~min}$, respectively. Several other species eluting at later retention times between 40 and 60 min may correspond to C1- and C4-oxidized species [9] (Fig. 6b).

\section{Discussion}

Although the discovery of LPMOs attracted considerable attention due to their beneficial use in biomass conversion 

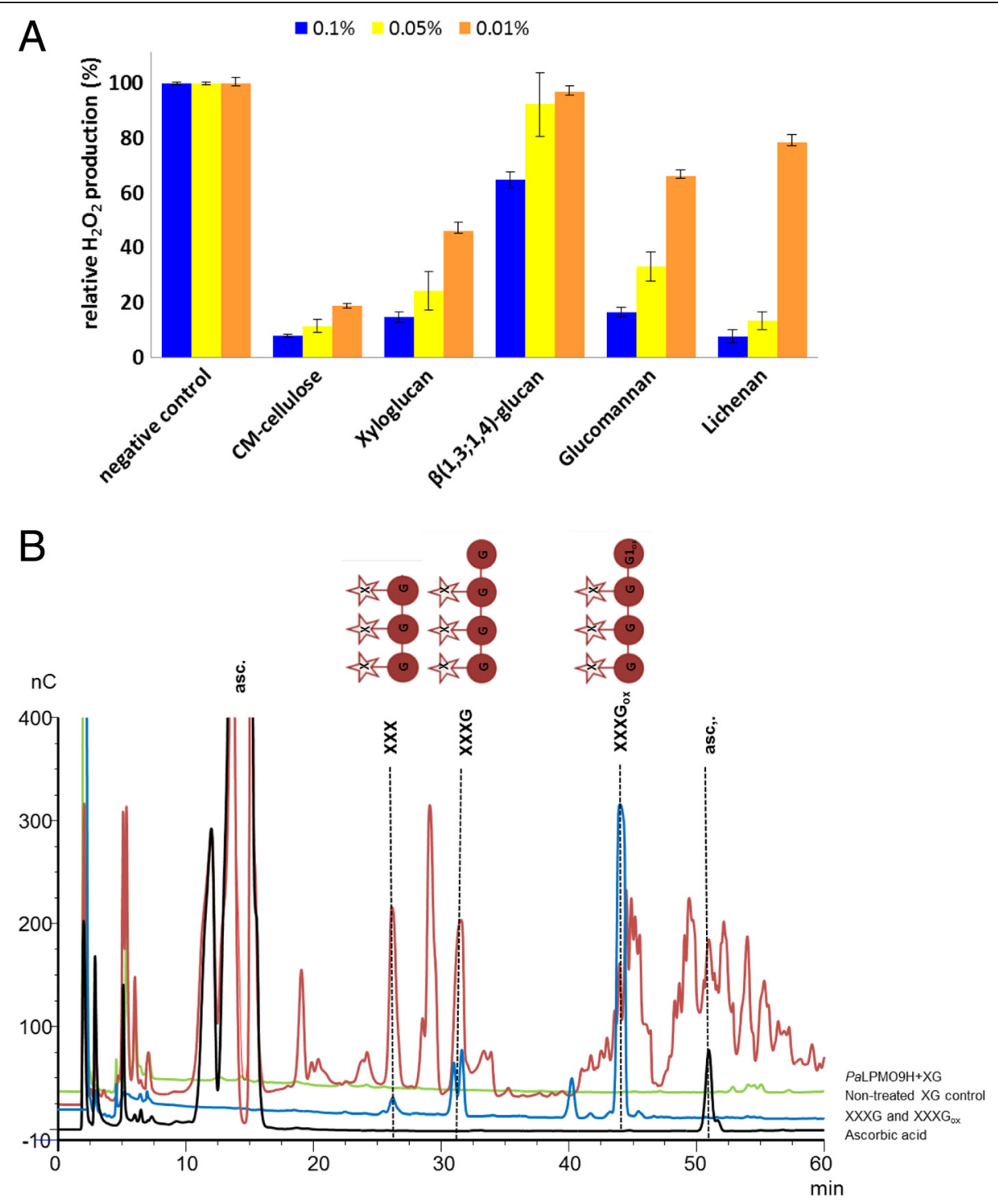

Fig. $6 \mathrm{PaLPMO9H}$ activity on polysaccharide substrates. a Relative production of $\mathrm{H}_{2} \mathrm{O}_{2}$ by $\mathrm{PaLPMO} 9 \mathrm{H}$ in the presence and/or absence of various polysaccharides substrates. $\mathbf{b}$ HPAEC chromatogram of products released from xyloglucan (XG) by action of PaLPMO9H in the presence of ascorbic acid. The C1-oxidized xyloglucan-derived heptasaccharide standard (XXXGox in blue) was prepared from XXXG (based on the nomenclature defined by [49]) using the PaCDHB as described in Material and Methods

to biofuels, to date, only 14 fungal AA9 LPMOs have been biochemically characterized $[4-10,14,31,36]$. In the present study, we selected six novel LPMOs and successfully characterized in depth three of them (PaLPMO9A, PaLPMO9E, and PaLPMO9H) due to their higher capacity of cellulose cleavage. Among them, the absence of methylation of the N-terminal histidine in PaLPMO9s heterologously expressed in P. pastoris was not detrimental for their functionality.

Approximately $20 \%$ of the fungal AA9 LPMOs possess a C-terminal CBM1 specific for cellulose [3], and in the genome of $P$. anserina, out of the 33 LPMOs, five harbor a CBM1 [26]. In this study, we revealed that modular
PaLPMO9s with anchored CBM1 release more oxidized oligosaccharides from cellulose than CBM1-less LPMOs. It is generally acknowledged that CBM1 potentiate the action of CAZymes including cellulases [29], hemicellulases [37], and oxidoreductases [38]. Indeed, carbohydratebinding modules (CBMs) target their appended catalytic domain to the insoluble substrate and increase the enzyme local concentration [39-41]. Recently, bacterial AA10 LPMOs integrated into designer cellulosomes were shown to promote overall cellulose degradation [42]. Therefore, the presence of CBMs in LPMOs is an important feature that should be considered for the design of enzyme cocktails for biomass deconstruction purposes. 
Three regioselective groups of AA9 LPMOs (types 1, 2 and 3) have been established based on sequence alignments $[8,12]$. In this study, we showed that PaLPMO9A and PaLPMO9E belong to type 3 (oxidation at both the $\mathrm{C} 1$ and $\mathrm{C} 4$ positions) and type 1 (oxidation at the $\mathrm{C} 1$ position only), respectively, in good agreement with the prediction made based on phylogenetic analyses [12]. However, we also evidenced using ionic chromatography and mass spectrometry that $\mathrm{PaLPMO} 9 \mathrm{H}$ behaved as a type 3 LPMO (oxidation at the $\mathrm{C} 1$ and $\mathrm{C} 4$ positions) although from the sequence, it was predicted as a type 2 LPMO (oxidation at the C4 position only) [12]. This classification based on alignments contains other exceptions since a subgroup of type 3 LPMOs (PMO3*) was recently created because the Myceliophtora thermophila AA9 LPMO (MYCTH_92668) was shown to oxidize at $\mathrm{C} 1$ position only [12]. The type 1 , type 2 , and type 3 classification based on the phylogenetic analysis using the entire amino acid sequence of AA9 catalytic modules might not be adapted to confidently predict AA9 LPMOs regioselectivity since only amino acids interacting directly with the substrate should be considered, but unfortunately so far, no 3D structure of AA9 LPMOs in complex with their substrate has been solved. Interestingly, AA9 protein sequences were divided into 16 subfamilies by finding short and conserved peptide motifs, but due to the low sequence similarity within the AA9 family, these subfamilies do not help to predict the substrate regioselectivity of AA9 LPMOs [43]. Meanwhile, further biochemical characterization is required to strengthen the prediction of AA9 LPMOs regioselectivity.

Time-course analysis of cellulose cleavage revealed that the dual action of $\mathrm{PaLPMO} 9 \mathrm{H}$ and $\mathrm{PaCDHB}$ were able to release soluble products at the early stage of the reaction. This result indicates that several oxidative cleavages occurred quite rapidly with the action of $\mathrm{PaLPMO} 9 \mathrm{H}$ that released $\mathrm{C} 4$ - and $\mathrm{C} 1$-oxidized species as well as non-oxidized species that are further oxidized at $\mathrm{C} 1$ position by $\mathrm{PaCDHB}$.

We further clearly evidenced that $\mathrm{PaLPMO} 9 \mathrm{H}$ was able to cleave cello-oligosaccharides using both $\mathrm{H}_{2} \mathrm{O}_{2}$ repression assays and ionic chromatography. $\mathrm{PaLPMO} 9 \mathrm{H}$ displayed affinity for non-cellulosic substrates including XG, $\beta$-glucans, and glucomannan. This broad substrate specificity towards cellodextrins and hemicellulose is not due to the presence of a CBM1 because PaLPMO9A and PaLPMO9E that also harbor a CBM1 did not display any activity on $\beta$-(1,4)-linked polysaccharides other than cellulose. Therefore, the minimal substrate requirement for PaLPMO9H is the presence of $\beta$-(1,4)-linked glucose in the backbone. In this regard, $\mathrm{PaLPMO} 9 \mathrm{H}$ is similar to NcLPMO9C from Neurospora crassa which has been recently shown to cleave oxidatively cello-oligosaccharides [30] as well as hemicellulose polysaccharides such as XG [9]. The main difference relies on the fact that NcLPMO9C cleaves only at the C4 position whereas $\mathrm{PaLPMO} 9 \mathrm{H}$ cleaves at both the $\mathrm{C} 1$ and $\mathrm{C} 4$ positions (although it seems to be predominantly at position $\mathrm{C} 4$ ). Therefore, the pattern of products obtained is different to NcLPMO9C with a broader diversity of product species released in the case of PaLPMO9H.

In the structural model of NcLPMO9C built using the crystal structure of NcLPMO9D (PDB 4EIR [44]), three asparagine residues exposed at the surface of NcLPMO9C were suggested to be involved in the interaction with oligosaccharides, constituting the +2 subsite [30]. In $\mathrm{PaLPMO} 9 \mathrm{H}$, the three asparagine residues (Asn25, Asn26, Asn27) are substituted by Ser25, Asn26, and Phe27 (Additional file 1: Figure S1). Thus, the presence of the three asparagine residues may not be strictly required for the binding of oligosaccharides. PaLPMO9H is the only AA9 LPMO to bear a phenylalanine residue at this position (Phe27) that would probably interact with the sugar through stacking interactions. Therefore, it is tempting to speculate that a strong +2 subsite is a prerequisite of LPMO binding to oligosaccharides. The presence of a phenylalanine residue in $\mathrm{PaLPMO} 9 \mathrm{H}$ may also explain its higher affinity for DP4 (Fig. 5a) compared to NcLPMO9C [30] and also the presence of oxidized DP2 products using cellopentaose or cellohexaose as substrate.

Concerning PaLPMO9H specificity for XG, it is interesting to note the amino acids spanning the loop from Gly64 to Ser83 are also found in NcLPMO9C that is to date the only AA9 LPMO displaying XG specificity [9]. This loop exposed at the surface in the structural model of NcLPMO9C [9] is a peculiarity of $\mathrm{PaLPMO} 9 \mathrm{H}$ and NcLPMO9C as compared to other characterized fungal AA9 LPMOs. Although XG activity has not been assessed for all the LPMOs studied to date, it is tempting to speculate that these loop-bearing charged residues (Glu66, Asp75, and Asp77) might be a prerequisite for XG specificity.

\section{Conclusions}

$P$. anserina represents an interesting model to study the oxidative deconstruction of lignocellulose since this coprophilous fungus displays an impressive array of genes encoding putative AA9 LPMOs. In this study, we start to unveil the reason for the existence of multiple AA9 LPMOs secreted naturally by this fungus. Indeed, the three enzymes characterized in depth have a different role by targeting different components of the plant cell wall (cellulose, soluble oligosaccharides, and hemicellulose) and/or generating different oxidized and nonoxidized products. In the present study, we clearly demonstrated that the broad substrate specificity of 
AA9 LPMOs towards oligosaccharides and noncellulosic polysaccharides is not unique to $N$. crassa. It opens new prospects concerning the biological role of LPMOs in the degradation and modification of nonrecalcitrant plant cell wall polysaccharides.

\section{Material and methods}

Cloning and production of $P$. anserina LPMO9s and CDH

The cloning of lpmo9A gene from $P$. anserina strain $\mathrm{S}$ mat $^{+}$, encoding PaLPMO9A (protein ID CAP73254), was described by Bey et al. [14] Genes encoding PaLPMOC (protein ID CAP68173), PaLPMO9D (protein ID CAP66744), PaLPMO9E (protein ID CAP67740), PaLPMO9F (protein ID CAP71839), PaLPMO9G (protein ID CAP73072), and PaLPMO9H (protein ID CAP61476) were codon optimized for $P$. pastoris (GenScript, Piscataway, USA) and further inserted into the vector pPICZ $\alpha A$ (Invitrogen, Cergy-Pontoise, France) using XhoI and $\mathrm{XbaI}$ restriction sites in frame with the $(\mathrm{His})_{6}$ tag (located at the $\mathrm{C}$ terminus of recombinant proteins). $P$. pastoris strain $\mathrm{X} 33$ and the $\mathrm{pPICZ} \alpha \mathrm{A}$ vector are components of the P. pastoris Easy Select Expression System (Invitrogen). All media and protocols are described in the Pichia expression manual (Invitrogen). Recombinant expression plasmids were sequenced to check the integrity of the corresponding sequences. Transformation of competent $P$. pastoris $\mathrm{X} 33$ was performed by electroporation with SacI-linearized pPICZ $\alpha$ A recombinant plasmids as described in [45]. Zeocin-resistant P. pastoris transformants were then screened for protein production. The best-producing transformant was grown in a 1 1 of BMGY containing $1 \mathrm{ml}^{-1} \mathrm{l}^{-1}$ of Pichia trace minerals 4

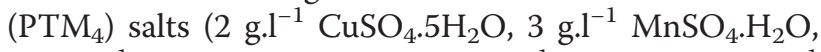
0.2 g. $1^{-1} \mathrm{Na}_{2} \mathrm{MoO}_{4} .2 \mathrm{H}_{2} \mathrm{O}, 0.02$ g. $.^{-1} \mathrm{H}_{3} \mathrm{BO}_{3}, 0.5$ g.l ${ }^{-1}$ $\mathrm{CaSO}_{4} .2 \mathrm{H}_{2} \mathrm{O}, 0.5$ g. $.^{-1} \mathrm{CaCl}_{2}, 12.5$ g.l l $^{-1} \mathrm{ZnSO}_{4} .7 \mathrm{H}_{2} \mathrm{O}, 22$ g. ${ }^{-1} \mathrm{FeSO}_{4} .7 \mathrm{H}_{2} \mathrm{O}$, biotin $0.2 \mathrm{~g} . \mathrm{l}^{-1}, \mathrm{H}_{2} \mathrm{SO}_{4} 1 \mathrm{ml.} \mathrm{l}^{-1}$ ) in shaken flasks at $28{ }^{\circ} \mathrm{C}$ in an orbital shaker (200 rpm) for $16 \mathrm{~h}$ to an $\mathrm{OD}_{600}$ of 2-6. Expression was induced by transferring cells into $200 \mathrm{ml}$ of BMMY containing 1 ml. $l^{-1}$ of $\mathrm{PTM}_{4}$ salts at $20{ }^{\circ} \mathrm{C}$ in an orbital shaker (200 $\mathrm{rpm}$ ) for another 3 days. Each day, the medium was supplemented with $3 \%(\mathrm{v} / \mathrm{v})$ methanol. Bioreactor production of the best-producing transformant was carried out in a 2-1 bioreactor Tryton (Pierre Guerin, Mauze, France) according to the $P$. pastoris fermentation process guidelines (Invitrogen).

\section{Enzyme purification}

After harvesting cells by centrifugation, the supernatant was dialyzed against buffer A (Tris- $\mathrm{HCl} 50 \mathrm{mM}$ pH 7.8, $\mathrm{NaCl} 150 \mathrm{mM}$, imidazole $10 \mathrm{mM}$ ) and loaded onto a His-Trap Resin (GE Healthcare, Buc, France) column $(1.60 \times 2.50$ or $1.60 \times 10 \mathrm{~cm})$ equilibrated with buffer A that was connected to an Äkta purifier 100 (GE
Healthcare). (His) ${ }_{6}$-tagged recombinant enzymes were eluted with buffer B (Tris- $\mathrm{HCl} 50 \mathrm{mM} \mathrm{pH} \mathrm{7.8,} \mathrm{NaCl}$ $150 \mathrm{mM}$, imidazole $500 \mathrm{mM}$ ). Fractions containing recombinant enzymes were pooled, concentrated, and dialyzed against sodium acetate buffer $50 \mathrm{mM}, \mathrm{pH} 4.8$.

\section{Protein analysis}

Proteins were loaded onto $10 \%$ SDS-PAGE gels (Thermo Fisher Scientific) and stained with Imperial Protein Stain (Thermo Fisher Scientific, IL, USA). The molecular mass under denaturating conditions was determined with reference standard proteins (PageRuler Prestained Protein Ladder, Thermo Fisher Scientific). Protein concentration was determined by using the Bradford assay (Bio-Rad, Marnes-la-Coquette, France). Tryptic digest of each purified recombinant protein was analyzed using MS as described in [27].

\section{Enzyme assays}

The activity of $\mathrm{CDH}$ was determined by monitoring the reduction of $0.2 \mathrm{mM}$ 2,6-DCPIP in $100 \mathrm{mM}$ sodium acetate buffer $(\mathrm{pH} 4.8)$ containing $10 \mathrm{mM}$ cellobiose as described in [46].

\section{Amplex red assay}

A fluorimetric assay based on Amplex Red and horseradish peroxidase was used as described previously [30, 31]. The reaction (total volume $100 \mu \mathrm{l}, 30{ }^{\circ} \mathrm{C}, 30 \mathrm{~min}$ ) was measured in $100 \mathrm{mM}$ sodium acetate buffer $\mathrm{pH}$ 6.0 containing $50 \mu \mathrm{M}$ Amplex Red (Sigma-Aldrich, Saint-Quentin Fallavier, France), 7.1 U.ml ${ }^{-1}$ horseradish peroxidase, 0.2 to $4 \mu \mathrm{M} \mathrm{PaLPMO}$, and $50 \mu \mathrm{M}$ ascorbate as reductant in water and fluorescence and was detected using an excitation wavelength of 560 $\mathrm{nm}$ and an emission wavelength of $595 \mathrm{~nm}$ using a Tecan Infinite M200 plate reader (Tecan, Männedorf, Switzerland). The specific activity was counted from $\mathrm{H}_{2} \mathrm{O}_{2}$ calibration curve, and the slope $(13,227$ counts $\left.\mu \mathrm{mol}^{-1}\right)$ was used to convert the fluorimeters' readout (counts $\mathrm{min}^{-1}$ ) into enzyme activity. For inhibition studies, the range of polysaccharides (cello-oligosaccharides DP4-DP6, PASC, CMC, $\beta(1,3 ; 1,4)$-glucan from barley, $\beta(1,3)$-glucan, lichenan, starch, glucomannan, laminarin, pectin, xylan, and XG) and their cellooligosaccharides derivatives were added to a final concentration of $0.1 \%(\mathrm{w} / \mathrm{v})$ and $3 \mathrm{mM}$, respectively. All measurements were performed in triplicates.

\section{Cellulose, xyloglucan, and cello-oligosaccharide cleavage assays}

All the cleavage assays (300 $\mu \mathrm{l}$ liquid volume) contained

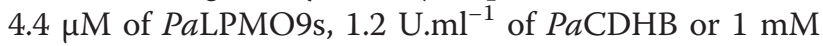
of ascorbate, and $0.1 \%(\mathrm{w} / \mathrm{v})$ PASC prepared from Avicel as described by [47] in $50 \mathrm{mM}$ sodium acetate 
buffer $\mathrm{pH} 4.8$ or $50 \mu \mathrm{M}$ of cello-oligosaccharides (Megazyme, Wicklow, Ireland) in $10 \mathrm{mM}$ sodium acetate buffer $\mathrm{pH}$ 4.8. The enzyme reactions were performed in 2$\mathrm{ml}$ tubes and incubated in a thermomixer (Eppendorf, Montesson, France) at $50{ }^{\circ} \mathrm{C}$ and $850 \mathrm{rpm}$. After $16 \mathrm{~h}$ of incubation, all the samples were boiled at $100{ }^{\circ} \mathrm{C}$ for 10 min to stop the enzymatic reaction and then centrifuged at $16,000 \mathrm{rpm}$ for $15 \mathrm{~min}$ at $4{ }^{\circ} \mathrm{C}$ to separate the soluble fraction from the remaining insoluble fraction before carbohydrate determination. For kinetic experiments, reactions were run as described above and stopped after 1 , $2,3,5,7,9,24,30$, and $48 \mathrm{~h}$ of incubation. Assays were performed as triplicate independent experiments. For $\mathrm{XG}$, the reaction mixture $(300 \mu \mathrm{l}$ liquid volume) contained $4.4 \mu \mathrm{M}$ of PaLPMO9H, $1 \mathrm{mM}$ of ascorbate, and $0.2 \%(\mathrm{w} / \mathrm{v})$ tamarind XG (Megazyme) in $50 \mathrm{mM}$ sodium acetate buffer $\mathrm{pH}$ 4.8. The enzyme reactions were performed in 2-ml tubes and proceed as described above. Assays were performed as triplicate independent experiments.

\section{Analysis of oxidized and non-oxidized oligosaccharides}

Mono-, oligosaccharides and their corresponding aldonic acid forms generated after PASC, oligosaccharides, and XG cleavage were analyzed by ionic chromatography (HPAEC) as described by [9] and [32] using nonoxidized oligosaccharides (Megazyme) as standards. Corresponding C1-oxidized standards (from DP2 to DP6) were produced from non-oxidized cello-oligosaccharides by $\mathrm{PaCDHB}$ treatment. All assays were carried out in triplicate.

\section{Mass spectrometry}

Products resulting from enzyme reaction in water were also analyzed by MS and two types of mass measurements were performed on the samples: firstly, a mass profile was done by matrix-assisted laser desorption/ ionization (MALDI)-time-of-flight (TOF) MS; ions of interest were further fragmented by collision-induced dissociation on an ESI MS/MS instrument. For MALDITOF MS measurements, an ionic preparation of 2,5dihydroxybenzoic acid (DHB) and N,N-dimethylaniline (DMA) was used as the MALDI matrix, as described in [48]. Briefly, the matrix consists of an equimolar mixture of DHB and DMA (DHB $100 \mathrm{mg} \cdot \mathrm{ml}^{-1}$, in $\mathrm{H}_{2} \mathrm{O}$ /acetonitrile/DMA (1:1:0.02)) and was mixed with the samples in a 1:1 ratio $(\mathrm{v} / \mathrm{v})$, and the mixture $(1 \mu \mathrm{L})$ was deposited on a polished steel MALDI target plate. MALDI measurements were then performed on an Autoflex Speed MALDI-TOF/TOF spectrometer (Bruker Daltonics, Bremen, Germany) equipped with a Smartbeam laser (355 $\mathrm{nm}, 200 \mathrm{~Hz}$ ) and controlled using the Flex Control 3.0 software package. The mass spectrometer was operated with positive polarity in a reflectron mode, and spectra were acquired in the range of $500-2000 \mathrm{~m} / \mathrm{z}$. For ESI MS/MS measurements, experiments were performed on a Synapt G2Si high-definition mass spectrometer (Waters Corp., Manchester, UK). Samples were diluted 100-fold in $\mathrm{MeOH} / \mathrm{H}_{2} \mathrm{O}(1: 1, \mathrm{v} / \mathrm{v})$ and infused at $5 \mu \mathrm{L} \cdot \mathrm{min}^{-1}$ in the instrument. The instrument was operated in a positive ionization mode in the so-called sensitivity mode, with an ESI capillary voltage of $3 \mathrm{kV}$ and a sampling cone voltage of $100 \mathrm{~V}$. Fragmentation was done by collision-induced dissociation in the transfer cell of the instrument, using appropriate collision energies depending on the precursor. Data acquisition was carried out using MassLynx software (V4.1) over a mass range of $100-1500 \mathrm{~m} / \mathrm{z}$.

\section{Additional file}

Additional file 1: Functional characterization of a set of fungal AA9
lytic polysaccharide monooxygenases secreted by Podospora
anserina. Table S1. Amino-acid identities of the PaLPMO9s studied.
Table S2. Identification of the N-terminal peptides bearing the first
histidine residue using LC-MS/MS. Figure S1. Multiple sequence alignment
of $17 \mathrm{LPMO9S}$ including 12 sequences of characterized LPMO9s and the
PaLPMO9s characterized in this Study. Figure S2. Electrophoretic analyses
of purified recombinant PaLPMO9D, PaLPMO9E, PaLPMO9F, PaLPMO9G,
PaLPMO9H and PaCDHB enzymes. Figure S3. Mass Spectrometry analysis of
degradation products generated from PASC by PaLPMO9E in the presence
of ascorbic acid. Figure S4. HPAEC chromatogram of products released from
cellopentaose by action of PaLPMO9H in the presence of ascorbic acid or
PaCDHB.

\section{Abbreviations}

AA: auxiliary activity enzyme; CBM: carbohydrate-binding module; $\mathrm{CDH}$ : cellobiose dehydrogenase; CMC: carboxymethyl cellulose; DHB: 2,5-dihydroxybenzoic acid; DMA: N,N-dimethylaniline; DP: degree of polymerization; LPMO: lytic polysaccharide monooxygenase; MS: mass spectrometry; PaLPMO9: Podospora anserina AA9 LPMO; PASC: phosphoric acid swollen cellulose; XG: xyloglucan; XXXG: xyloglucan-derived heptasaccharide.

\section{Competing interests}

The authors declare that they have no competing interests.

\section{Authors' contributions}

CBG, SGA, and JGB designed the research. CBG, SGA, SGR, CC, MH, SZ, HR, $M F$, and DR performed the research. CBG, SGA, IG, ER, HR, MF, DR, and JGB analyzed the data and JGB drafted the manuscript. All authors read and approved the final version of the manuscript.

\section{Acknowledgements}

This study was carried out in the frame of Futurol and Funcopper projects with financial support from the OSEO and the AMIDEX foundation (project A*M-AAP-EI-13-13-130115-15.37), respectively. The authors thank H.P. Fierobe (CNRS Marseille) for his kind help in the preparation of PASC, M. Belgazhi (UMR 7286, CRN2M Marseille) for the mass spectrometry analyses, D. Chevret (INRA PAPPSO Jouy en Josas) for proteomic analyses, and B. Henrissat (AFMB Marseille) for stimulating discussions. Finally, we would like to thank the reviewers for all the comments that helped us to improve the manuscript.

\section{Author details}

${ }^{1}$ INRA, UMR1163 Biodiversité et Biotechnologie Fongiques, Faculté des Sciences de Luminy, ESIL Polytech, F-13288 Marseille, France. ${ }^{2}$ Polytech Marseille, Aix Marseille Université, F-13288 Marseille, France. ${ }^{3}$ Institute of Chemistry, Slovak Academy of Sciences, 84538 Bratislava, Slovakia. ${ }^{4}$ INRA, Plateforme BIBS, Unité de Recherche Biopolymères, Interactions,

Assemblages, 44316 Nantes, France. 
Received: 16 February 2015 Accepted: 12 June 2015

\section{Published online: 20 June 2015}

\section{References}

1. Himmel ME, Ding S-Y, Johnson DK, Adney WS, Nimlos MR, Brady JW, et al. Biomass recalcitrance: engineering plants and enzymes for biofuels production. Science. 2007;315:804-7.

2. Vaaje-Kolstad G, Westereng B, Horn SJ, Liu Z, Zhai H, Sørlie M, et al. An oxidative enzyme boosting the enzymatic conversion of recalcitrant polysaccharides. Science. 2010;330:219-22.

3. Harris PV, Welner D, McFarland KC, Re E, Navarro Poulsen JC, Brown K, et al. Stimulation of lignocellulosic biomass hydrolysis by proteins of glycoside hydrolase family 61: structure and function of a large, enigmatic family. Biochemistry. 2010;49:3305-16.

4. Westereng B, Ishida T, Vaaje-Kolstad G, Wu M, Eijsink VGH, Igarashi K, et al. The putative endoglucanase PCGH61D from Phanerochaete chrysosporium is a metal-dependent oxidative enzyme that cleaves cellulose. PLoS One. 2011;6, e27807.

5. Langston JA, Shaghasi T, Abbate E, Xu F, Vlasenko E, Sweeney MD Oxidoreductive cellulose depolymerization by the enzymes cellobiose dehydrogenase and glycoside hydrolase 61. Appl Environ Microbiol. 2011;77:7007-15.

6. Phillips CM, Beeson WT, Cate JH, Marletta MA. Cellobiose dehydrogenase and a copper-dependent polysaccharide monooxygenase potentiate cellulose degradation by Neurospora crassa. ACS Chem Biol. 2011;6:1399-406.

7. Quinlan RJ, Sweeney MD, Lo Leggio L, Otten H, Poulsen J-CN, Johansen KS, et al. Insights into the oxidative degradation of cellulose by a copper metalloenzyme that exploits biomass components. Proc Natl Acad Sci U S A. 2011;108:15079-84.

8. Beeson WT, Phillips CM, Cate JHD, Marletta MA. Oxidative cleavage of cellulose by fungal copper-dependent polysaccharide monooxygenases. J Am Chem Soc. 2012;134:890-2.

9. Agger JW, Isaksen T, Várnai A, Vidal-Melgosa S, Willats WGT, Ludwig R, et al. Discovery of LPMO activity on hemicelluloses shows the importance of oxidative processes in plant cell wall degradation. Proc Natl Acad Sci U S A. 2014;111:6287-92.

10. Vu W, Beeson WT, Span EA, Farquhar ER, Marletta MA. A family of starch-active polysaccharide monooxygenases. Proc Natl Acad Sci U S A. 2014;111:13822-7.

11. Lo Leggio L, Simmons TJ, Poulsen J-CN, Frandsen KEH, Hemsworth GR, Stringer MA, et al. Structure and boosting activity of a starch-degrading lytic polysaccharide monooxygenase. Nat Commun. 2015;6:5961.

12. Van Vu V, Beeson WT, Phillips CM, Cate JHD, Marletta MA. Determinants of regioselective hydroxylation in the fungal polysaccharide monooxygenases. J Am Chem Soc. 2014;136:562-5.

13. Morgenstern I, Powlowski J, Tsang A. Fungal cellulose degradation by oxidative enzymes: from dysfunctional GH61 family to powerful lytic polysaccharide monooxygenase family. Brief Funct Genom. 2014;13:471-81.

14. Bey M, Zhou S, Poidevin L, Henrissat B, Coutinho PM, Berrin JG, et al. Cello-oligosaccharide oxidation reveals differences between two lytic polysaccharide monooxygenases (family GH61) from Podospora anserina. Appl Environ Microbiol. 2013;79:488-96.

15. Lombard V, Golaconda Ramulu H, Drula E, Coutinho PM, Henrissat B. The carbohydrate-active enzymes database (CAZy) in 2013. Nucleic Acids Res. 2014;42:1-6.

16. Levasseur A, Drula E, Lombard V, Coutinho PM, Henrissat B. Expansion of the enzymatic repertoire of the CAZy database to integrate auxiliary redox enzymes. Biotechnol Biofuels. 2013;6:41.

17. Forsberg Z, Vaaje-Kolstad G, Westereng B, Bunæs AC, Stenstrøm Y, MacKenzie A, et al. Cleavage of cellulose by a CBM33 protein. Protein Sci. 2011;20:1479-83.

18. Hemsworth GR, Taylor EJ, Kim RQ, Gregory RC, Lewis SJ, Turkenburg JP, et al. The copper active site of CBM33 polysaccharide oxygenases. J Am Chem Soc. 2013;135:6069-77.

19. Sygmund C, Kracher D, Scheiblbrandner S, Zahma K, Felice AKG, Harreither W, et al. Characterization of the two Neurospora crassa cellobiose dehydrogenases and their connection to oxidative cellulose degradation. Appl Environ Microbiol. 2012;78:6161-71.

20. Zamocky M, Ludwig R, Peterbauer C, Hallberg BM, Divne C, Nicholls P, et al. Cellobiose dehydrogenase - a flavocytochrome from wood-degrading, phytopathogenic and saprotropic fungi. Curr Protein Pept Sci. 2006;7:255-80.
21. Espagne E, Lespinet O, Malagnac F, Da Silva C, Jaillon O, Porcel BM, et al. The genome sequence of the model ascomycete fungus Podospora anserina. Genome Biol. 2008;9:R77.

22. Couturier M, Navarro D, Olivé C, Chevret D, Haon M, Favel A, et al. Post-genomic analyses of fungal lignocellulosic biomass degradation reveal the unexpected potential of the plant pathogen Ustilago maydis. BMC Genomics. 2012;13:57.

23. Ray A, Saykhedkar S, Ayoubi-Canaan P, Hartson SD, Prade R, Mort AJ. Phanerochaete chrysosporium produces a diverse array of extracellular enzymes when grown on sorghum. Appl Microbiol Biotechnol. 2012;93:2075-89.

24. Fernandez-fueyo E, Ruiz-dueñas FJ, Ferreira P, Floudas D, Hibbett DS, Kües U, et al. Comparative genomics of Ceriporiopsis subvermispora and Phanerochaete chrysosporium provide insight into selective ligninolysis. Proc Natl Acad Sci. 2012;109:5458-63.

25. O'Connell RJ, Thon MR, Hacquard S, Amyotte SG, Kleemann J, Torres MF et al. Lifestyle transitions in plant pathogenic Colletotrichum fungi deciphered by genome and transcriptome analyses. Nat Genet. 2012:44:1060-5.

26. Poidevin L, Berrin JG, Bennati-Granier C, Levasseur A, Herpoël-Gimbert I, Chevret D, et al. Comparative analyses of Podospora anserina secretomes reveal a large array of lignocellulose-active enzymes. Bioresour Technol. 2014;98:7457-69.

27. Navarro D, Rosso M-N, Haon M, Olivé C, Bonnin E, Lesage-Meessen L, et al. Fast solubilization of recalcitrant cellulosic biomass by the basidiomycete fungus Laetisaria arvalis involves successive secretion of oxidative and hydrolytic enzymes. Biotechnol Biofuels. 2014;7:143.

28. Turbe-Doan A, Arfi Y, Record E, Estrada-Alvarado I, Levasseur A. Heterologous production of cellobiose dehydrogenases from the basidiomycete Coprinopsis cinerea and the ascomycete Podospora anserina and their effect on saccharification of wheat straw. Appl Microbiol Biotechnol. 2013;97:4873-85

29. Couturier M, Feliu J, Haon M, Navarro D, Lesage-Meessen L, Coutinho PMM, et al. A thermostable GH45 endoglucanase from yeast: impact of its atypical multimodularity on activity. Microb Cell Fact. 2011;10:103.

30. Isaksen T, Westereng B, Aachmann FL, Agger JW, Kracher D, Kittl R, et al. A C4-oxidizing lytic polysaccharide monooxygenase cleaving both cellulose and cello-oligosaccharides. J Biol Chem. 2014;289:2632-42.

31. Kittl R, Kracher D, Burgstaller D, Haltrich D, Ludwig R. Production of four Neurospora crassa lytic polysaccharide monooxygenases in Pichia pastoris monitored by a fluorimetric assay. Biotechnol Biofuels. 2012;5:79.

32. Westereng B, Agger JW, Horn SJ, Vaaje-Kolstad G, Aachmann FL, Stenstrøm $\mathrm{YH}$, et al. Efficient separation of oxidized cello-oligosaccharides generated by cellulose degrading lytic polysaccharide monooxygenases. J Chromatogr A. 2013;1271:144-52.

33. Saloheimo M, Nakari-SetaLa T, Tenkanen M, Penttila M. CDNA cloning of a Trichoderma reesei cellulase and demonstration of endoglucanase activity by expression in yeast. Eur J Biochem. 1997;249:584-91.

34. Karlsson J, Saloheimo M, Siika-aho M, Tenkanen M, Penttilä M, Tjerneld F. Homologous expression and characterization of Cel61A (EG IV) of Trichoderma reesei. Eur J Biochem. 2001;268:6498-507.

35. Forsberg Z, Mackenzie AK, Sørlie M, Røhr ÅK, Helland R, Arvai AS, et al. Structural and functional characterization of a conserved pair of bacterial cellulose-oxidizing lytic polysaccharide monooxygenases. Proc Natl Acad Sci U S A. 2014;111:8446-51.

36. Hemsworth GR, Davies GJ, Walton PH. Recent insights into coppercontaining lytic polysaccharide mono-oxygenases. Curr Opin Struct Biol. 2013;23:660-8.

37. Pham TA, Berrin JG, Record E, To KA, Sigoillot JC. Hydrolysis of softwood by Aspergillus mannanase: role of a carbohydrate-binding module. J Biotechnol. 2010;148:163-70

38. Ravalason H, Herpoël-Gimbert I, Record E, Bertaud F, Grisel S, de Weert S, et al. Fusion of a family 1 carbohydrate binding module of Aspergillus niger to the Pycnoporus cinnabarinus laccase for efficient softwood kraft pulp biobleaching. J Biotechnol. 2009;142:220-6.

39. Bolam DN, Ciruela A, Mcqueen-mason S, Simpson P, Williamson MP, Rixon $\mathrm{JE}$, et al. Pseudomonas cellulose-binding domains mediate their effects by increasing enzyme substrate proximity. Biochem J. 1998;331:775-81.

40. Tomme P, Van Tilbeurgh H, Pettersson G, Van Damme J, Vandekerckhove J, Knowles J, et al. Studies of the cellulolytic system of Trichoderma reesei QM 9414. Analysis of domain function in two cellobiohydrolases by limited proteolysis. Eur J Biochem. 1988;170:575-81. 
41. Reinikainen $\mathrm{T}$, Teleman $\mathrm{O}$, Teeri $\mathrm{TT}$. Effects of $\mathrm{pH}$ and high ionic strength on the adsorption and activity of native and mutated cellobiohydrolase I from Trichoderma reesei. Proteins. 1995;22:392-403.

42. Arfi Y, Shamshoum M, Rogachev I, Peleg Y, Bayer EA. Integration of bacterial lytic polysaccharide monooxygenases into designer cellulosomes promotes enhanced cellulose degradation. Proc Natl Acad Sci U S A. 2014;111:9109-14.

43. Busk PK, Lange L. Function-based classification of carbohydrate-active enzymes by recognition of short, conserved peptide motifs. Appl Environ Microbiol. 2013;79:3380-91.

44. Li X, Beeson IV WT, Phillips CM, Marletta MA, Cate JHD. Structural basis for substrate targeting and catalysis by fungal polysaccharide monooxygenases. Structure. 2012;20:1051-61.

45. Couturier M, Haon M, Coutinho PM, Henrissat B, Lesage-Meessen L, Berrin JG. Podospora anserina hemicellulases potentiate the Trichoderma reesei secretome for saccharification of lignocellulosic biomass. Appl Environ Microbiol. 2011;77:237-46.

46. Bey M, Berrin JG, Poidevin L, Sigoillot JC. Heterologous expression of Pycnoporus cinnabarinus cellobiose dehydrogenase in Pichia pastoris and involvement in saccharification processes. Microb Cell Fact. 2011;10:113.

47. Wood TM. Preparation of crystalline, amorphous, and dyed cellulase substrates. Methods Enzym. 1988;160:19-25.

48. Ropartz D, Bodet P-E, Przybylski C, Gonnet F, Daniel R, Fer M, et al. Performance evaluation on a wide set of matrix-assisted laser desorption ionization matrices for the detection of oligosaccharides in a high-throughput mass spectrometric screening of carbohydrate depolymerizing enzymes. Rapid Commun Mass Spectrom. 2011;25:2059-70

49. Fry SC, York WS, Albersheim P, Darvill A, Hayashi T, Joseleau JP, et al. An unambiguous nomenclature for xyloglucan-derived oligosaccharides. Physiol Plant. 1993;89:1-3.

\section{Submit your next manuscript to BioMed Central and take full advantage of:}

- Convenient online submission

- Thorough peer review

- No space constraints or color figure charges

- Immediate publication on acceptance

- Inclusion in PubMed, CAS, Scopus and Google Scholar

- Research which is freely available for redistribution 